\title{
Singing-related reorganization of the song motor circuit is accompanied by a shift in hormonal modulation of song
}

\author{
Mariana D. Rocha ${ }^{1}$, Jes Dreier ${ }^{2}$, Jonathan Brewer ${ }^{2}$, Manfred Gahr ${ }^{1}$, Michiel Vellema ${ }^{1,3}$ \\ ${ }^{1}$ Department of Behavioural Neurobiology, Max Planck Institute for Ornithology, Seewiesen, \\ Germany \\ 2 Department of Biochemistry and Molecular Biology, University of Southern Denmark, \\ Odense, Denmark \\ ${ }^{3}$ Department of Biology, University of Southern Denmark, Odense, Denmark
}

\section{Abstract}

Sex hormones are essential modulators of birdsong. Testosterone, and its active androgenic and estrogenic metabolites, $5 \alpha$-dihydrotestosterone (DHT) and estradiol, can re-shape the brain circuits responsible for song learning and production. The differential mechanisms of action of these different hormones during song development and song maintenance are, nonetheless, not fully understood. Here we demonstrate that unlike testosterone, DHT treatment does not induce singing behavior in naïve adult female canaries that have never previously produced song. However, in birds with previous testosterone-induced singing experience, DHT alone is enough to promote the re-acquisition of high quality songs, even after months of silence. In addition, we show that the synaptic reorganization that accompanies vocal motor skill development requires more than DHT-induced androgen receptor activation. These results indicate that vocal motor practice will persistently modify the hormone-sensitive brain circuit responsible for song production, suggesting a mechanistic differentiation in the hormone-dependent regulation of the initial vocal motor skill acquisition and later re-acquisition. 


\section{Introduction}

Sex hormones are critical modulators of adult neuroplasticity and behavior. Sex hormones can either be produced locally in the brain or be synthesized in the gonads and reach the brain through blood circulation (Diotel et al., 2018). Additionally, circulating testosterone can be converted in the brain into its active metabolites through enzymatic action: into DHT ( $5 \alpha-$ dihydrotestosterone) by $5 \alpha$-reductase, or into estradiol (17 $\beta$-estradiol) via the enzyme aromatase. Through their interactions with androgen and estrogen receptors in the brain, sex hormones can mold brain circuits, and thus shape animal behavior in complex ways (Chen et al., 2013; Diotel et al., 2018; Gahr, 2004; Galea, 2008).

Birdsong is a complex motor behavior produced as a result of self-reinforced vocal imitation and exhibits many parallels to human speech (Bolhuis et al., 2010). Birdsong is known to be modulated by sex hormones in the song system, the network of interconnected brain nuclei responsible for controlling song learning and production. Seasonal changes in the vocal performance of songbirds are highly correlated with changes in testosterone levels (Nottebohm et al., 1987; Smith et al., 1997; Tramontin and Brenowitz, 2000; Voigt and Leitner, 2008). These changes in testosterone levels are accompanied by gross anatomical and cytoarchitectural restructuring of the song system (Balthazart et al., 2008; Gahr, 1990b; Kafitz et al., 1999; Kirn et al., 1994; Nottebohm, 1981; Thompson and Brenowitz, 2005; Vellema et al., 2014). Furthermore, many songbird species are sexually dimorphic in song behavior. In many species, such as the canary (Serinus canaria), only males sing. Female canaries rarely sing spontaneously, and never produce high quality songs under natural conditions (Pesch and Güttinger, 1985). However, these naturally non-singing birds can be persuaded to sing when treated with testosterone, as well as by a combination of both its active metabolites, DHT and estradiol (Devoogd and Nottebohm, 1981). Moreover, testosterone-induced changes in female canaries also include the masculinization of the song system (Nottebohm, 1980).

In a previous study we let female canaries develop their vocal motor skills by long-term implantation with testosterone, followed by implant removal to cease song production, and then by a second testosterone treatment to investigate the re-development of vocal motor skills (Vellema et al., 2019). We found that these birds showed a slow development of song features in the first treatment, with a faster re-acquisition during the second treatment. Furthermore, we provided evidence that the accelerated re-acquisition of vocal motor 
performance could be mediated by a lasting reorganization of the song motor circuit. Testosterone-induced singing led to substantial dendritic spine pruning in brain nucleus HVC of the song system, which was maintained after testosterone removal, whereas dendritic spine densities in another song premotor nuclei, nucleus RA, remained unaffected.

Here we demonstrate that unlike testosterone, DHT treatment of naive female canaries does not affect dendritic spine densities in nucleus HVC, and is insufficient to stimulate the development of song. However, once birds acquired singing skills through testosterone treatment, but stopped singing for some time, DHT alone was enough to stimulate the reacquisition of previously acquired levels of song performance. These findings suggest that a significant shift in the hormone regulation of song production takes place during song learning, simplifying the mechanisms behind the re-acquisition of vocal motor performance. Such a simplified regulation of hormone-dependent vocal motor acquisition in experienced animals may play an important function in the ability to quickly recover previously acquired levels of vocal performance. 


\section{Results}

\section{Singing experience leads to a shift in hormonal modulation of song}

We administered subcutaneous implants filled with the steroid hormone DHT $(5 \alpha-$ dihydrotestosterone) to both naïve adult female canaries, who had never previously experienced neither hormonal treatment nor singing, and experienced females that had prior testosterone-induced singing practice, while recording their vocal output (figure 1A).

In line with previous reports (Devoogd and Nottebohm, 1981), we show that treating naïve female canaries with DHT alone fails to stimulate singing (figure 1B). Subsequent testosterone treatment did, however, induce singing in the same individuals, confirming that the absence of song development during DHT treatment is not caused by an inability to sing, but is due to the ineffectiveness of DHT to stimulate song production in naïve animals. Surprisingly, DHT treatment of experienced female canaries that were previously allowed to undergo testosterone-induced song development did, on the other hand, succeed in stimulating singing (figure $1 \mathrm{C}$ ).

Additionally, the observed song patterns that emerged during DHT treatment were very similar to the song patterns that developed during the preceding testosterone treatment (figure 1D and E). Both the distribution of syllable rates (SR) and frequency modulations (FM) correlated strongly between the first testosterone treatment and the subsequent DHT treatment within individuals (correlation coefficient, CC: $0.78 \pm 0.10$ for SR, and $0.84 \pm 0.04$ for FM), with significantly higher $C^{\prime}$ 's than when cross-correlated between individuals $(P<$ 0.01, paired t-test). These findings indicate that DHT treatment can stimulate the development of song of similar quality as testosterone treatment, but only in birds that had previous testosterone-induced singing experience.

It is known that either testosterone, or a combination of both estradiol and $\mathrm{DHT}$, is required to induce singing in naïve female canaries (Devoogd and Nottebohm, 1981; this publication), or in castrated male canaries (Sartor et al., 2005), suggesting that the activation of both AR and ER is needed to trigger song output. Our findings indicate that after an initial hormoneinduced singing experience, the hormonal cascades modulating singing behavior are simplified, making AR receptor activation sufficient to trigger singing. 
A.
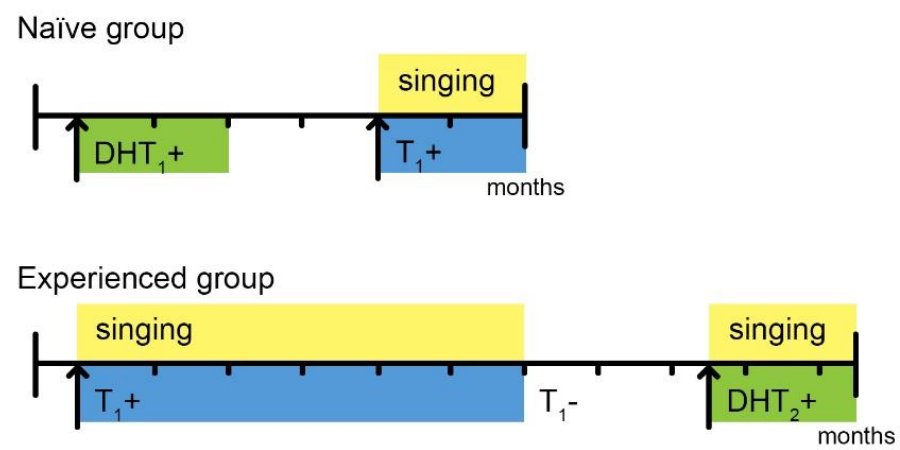

B.

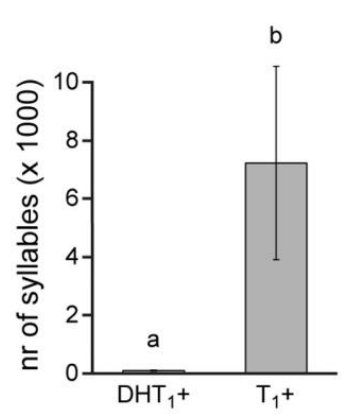

D.

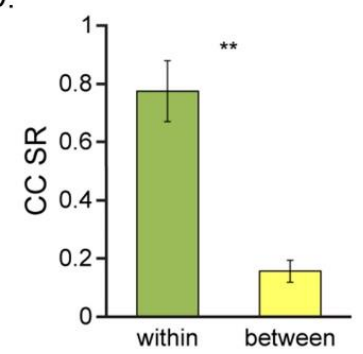

C

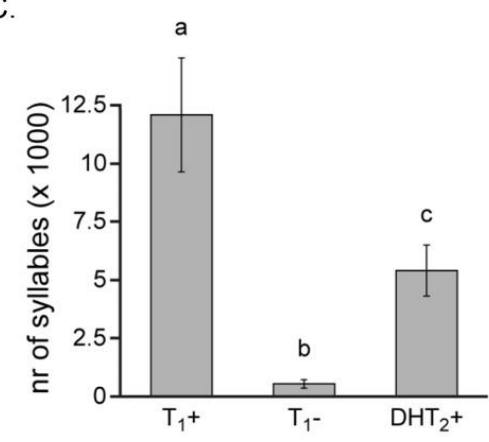

E.

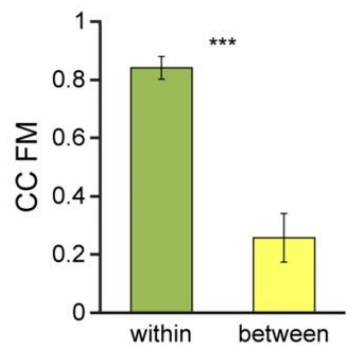

Figure 1: DHT triggers song development only after prior testosterone-induced singing experience. (A) Experimental setup. The naïve group was treated with $\mathrm{DHT}\left(\mathrm{DHT}_{1}+\right)$ for 2 months, which failed to trigger song production, and subsequently treated with testosterone $\left(T_{1}+\right)$ to confirm the singing ability of the individuals in this group. The experienced group was first treated with testosterone $\left(\mathrm{T}_{1}+\right)$ and allowed to practice singing for 6 months, after which testosterone was removed and song production abolished for 2.5 months $\left(T_{1-}\right)$, followed by DHT implantation for 2 months ( $\mathrm{DHT}_{2}+$ ), which eliciting singing. (B) DHT treatment of naïve female canaries $\left(\mathrm{DHT}_{1}+\right.$ ) did not induce song production, while subsequent testosterone implantation $\left(\mathrm{T}_{1}+\right)$ of the same individuals significantly increased the daily number of produced song syllables. (C) Another group of birds was stimulated to sing with testosterone $\left(T_{1}+\right)$, and ceased singing after testosterone withdrawal $\left(T_{1}-\right)$. Subsequent $D H T$ treatment $\left(\mathrm{DHT}_{2}+\right)$ of these individuals significantly increased the daily number of produced song syllables. (D and E) Similarity in song patterns after subsequent hormone treatments. Both the distribution of syllable rates (SR, D) and frequency modulations (FM, E) correlated strongly between $\mathrm{T}_{1}+$ and $\mathrm{DHT}_{2}+$ within individuals (green bars), and correlation coefficients (CC) were significantly higher than when cross-correlated between individuals (yellow bars). Columns represent the mean \pm SEM ( $a, b, c: P<0.05$, Wilcoxon signed-rank test, $n=5$ for $B$ and $n=6$ for $C ; * * P<0.01, * * * P \leq 0.001$, paired t-test; $\mathrm{n}=6$ for $\mathrm{D}$ and $\mathrm{E}$ ). 


\section{DHT-independent synaptic pruning}

In our previous study we found that testosterone-induced singing experience led to pronounced dendritic spine pruning in HVC, with dendritic spine densities remaining low as testosterone was removed and song production ceased (Vellema et al., 2019). Whether the reduction in spines is driven by the behavioral activation of the song motor circuit or whether spine pruning is directly induced by activation of the AR-pathway in HVC has remained elusive. By comparing dendritic spine densities in Golgi-stained HVC tissue of DHT-implanted naïve $\left(\mathrm{DHT}_{1}+\right)$ and experienced female canaries $\left(\mathrm{DHT}_{2}+\right)$ we found that, contrary to testosterone treatment, DHT treatment of naïve females did not lead to synaptic pruning in HVC (figure $2 \mathrm{~A})$. Both groups lacking singing experience $\left(\mathrm{C}\right.$ and $\left.\mathrm{DHT}_{1+}\right)$ showed similarly high dendritic spine densities in HVC. On the other hand, singing DHT-treated experienced birds ( $\left.\mathrm{DHT}_{2+}\right)$ had significantly lower HVC dendritic spine densities, similar to the other two treatment groups who experienced hormone-induced song development ( $T_{1+}$ and $T_{1-;}$ figure $\left.2 A\right)$.

After testosterone treatment, we previously found that the strongest reduction in spines was detected in the range of dendrites with the highest spine density (Vellema et al., 2019). Here we calculated the probability distribution of HVC dendrite types for DHT-treated females, and confirm that the changes in HVC's synaptic circuit seems to mainly concern highly dense neurites. The ratio of dense dendrites in non-singing $\mathrm{DHT}$-implanted naïve $\left(\mathrm{DHT}_{1+}\right)$ females is similar to that of non-singing controls (C), whereas the ratio of dense dendrites is lower in all three groups that experienced testosterone-induced singing $\left(T_{1+}, T_{1-}\right.$, and $\mathrm{DHT}_{2+}$; figure $\left.2 \mathrm{~B}\right)$. These densely spiny neurites predominantly belong to putative $\mathrm{HVC}_{\mathrm{x}}$ neurons (Kornfeld et al., 2017), the permanent subpopulation of HVC projection neurons that are part of the pallialbasal ganglia-thalamic loop essential to vocal learning (Doupe et al., 2004).

Our results suggest that the observed changes in the HVC circuit are brought about by testosterone-induced activation of the vocal motor circuit, requiring more than AR activation alone. Furthermore, once consolidated, the HVC circuitry seems to be resistant to both testosterone removal and DHT treatment, as well as to singing practice offset or onset. 
A.

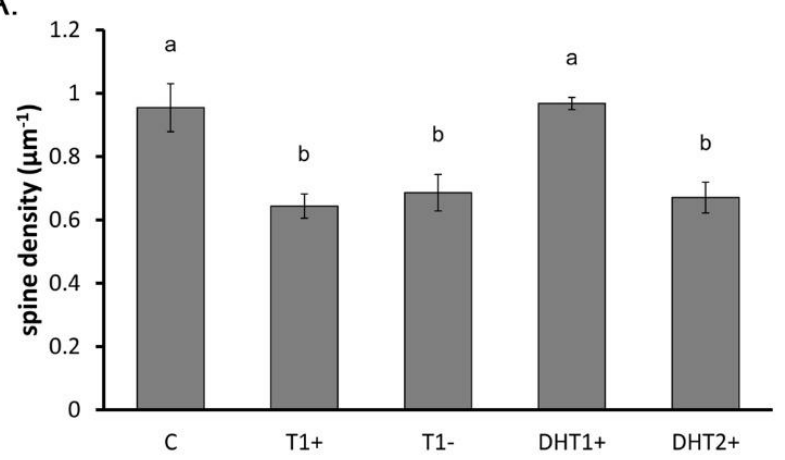

B.

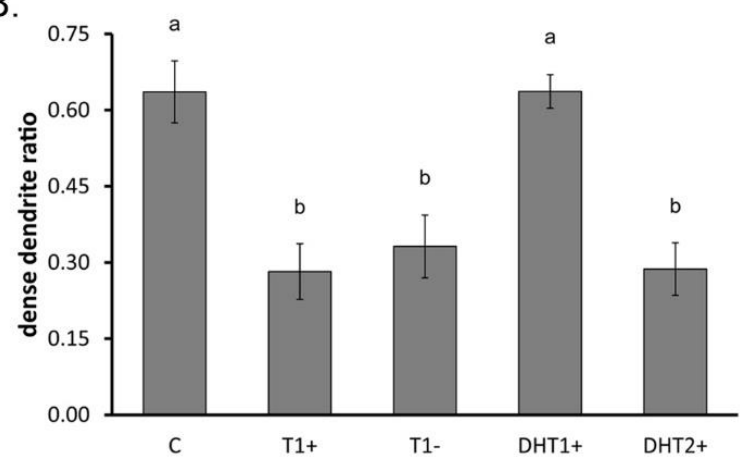

Figure 2. The singing-induced synaptic reorganization of HVC is independent of AR activation. (A) Compared to non-singing untreated control birds (C), spine densities were significantly reduced in testosterone-treated, singing birds $\left(\mathrm{T}_{1}+\right)$, but not in non-singing DHTtreated naïve females $\left(\mathrm{DHT}_{1}+\right)$. Spine densities remained significantly reduced up to 2.5 months after birds stopped singing by withdrawing testosterone $\left(T_{1^{-}}\right)$, as well as after subsequent DHT-induced singing practice for 2 months $\left(\mathrm{DHT}_{2}+\right)$. (B) Dense dendrite $(>0.8$ spines per $\mu \mathrm{m}$ of dendrite) ratios further illustrate significant similarities between naïve groups ( $\mathrm{C}$ and $\left.\mathrm{DHT}_{1}+\right)$ and birds who experienced singing practice $\left(\mathrm{T}_{1^{+}}, \mathrm{T}_{1^{-}}\right.$, and $\left.\mathrm{DHT}_{2}+\right)$. [a, $\mathrm{b}$ : $P<0.01$, ANOVA, $n=6$ animals. Data for groups $C_{,} T_{1}+$, and $T_{1}$ - taken from Vellema et al. (2019) with permission.] 


\section{Discussion}

In this study we show that the reorganization of the song motor circuit evoked by singing practice is accompanied by a shift in the hormonal cascades needed to trigger singing. The testosterone-induced practice of vocal motor skills lead to both a simplification of the song connectome by the elimination of superfluous synapses, as well as to a simplification of the sex hormone-modulated pathways required to elicit song behavior.

Both ER activation by estradiol as well as AR activation, by either testosterone or its more potent metabolite DHT, are required to trigger song acquisition in female canaries (DeVoogd and Nottebohm, 1981). The necessity for ER activation is supported by studies showing that active brain aromatase, the enzyme responsible for the synthesis of estradiol from testosterone, is needed to induce singing in testosterone-treated naïve females (Brenowitz and Lent, 2002, 2001; Fusani et al., 2003). However, here we show that if birds learned to sing once before, but stopped singing for some time, ER activation is no longer required and DHT alone is sufficient to induce the re-acquisition of song.

The mechanisms and gene cascades involved in this complex interplay between hormonal and behavioral effects on brain circuits are not fully understood. Previous studies revealed that testosterone-induced gene expression in HVC is related to cellular differentiation, axon, dendrite and synapse organization (Dittrich et al., 2014; Frankl-Vilches et al., 2015). Furthermore, whereas AR have been found in many song system nuclei, including both HVC and RA, ER have only been found in HVC (Gahr et al., 1987). This makes HVC the only song nucleus expressing both AR and ER, and many active genes in HVC contain androgen and/or estrogen response elements (Frankl-Vilches et al., 2015).

AR and ER are expressed in distinct cell populations within HVC (Gahr, 1990a), and ER are mainly restricted to $H V C_{x}$ projecting neurons (Gahr, 1990b). Interestingly, $H V C_{x}$ neurons are also the neuron population that is most strongly affected by spine pruning upon testosteroneinduced singing (figure 2B). Estrogens have been shown to affect dendritic spine density and induce the remodeling of synapse structure and function in mammals (Luine et al., 2018; Srivastava, 2012), as well as facilitate memory consolidation (Frick, 2015). Perhaps ER activation is responsible for promoting synaptic plasticity in $\mathrm{HVC}_{\mathrm{X}}$ neurons in a first singing experience, leading to the optimization of the motor circuit for song production. Once circuit optimization is accomplished, motor memories are stored in the responsible synaptic circuits, 
and the ER-activated gene cascades that promote synaptic plasticity become unnecessary or even detrimental for the preservation of these optimized circuits. Thereafter, ER-activated gene cascades may thus permanently be switched off in order to preserve the stored motor memories. Future investigations should explore gene expression across different cell populations in HVC to determine the experience-dependent gene cascades involved in the hormonal regulation of song behavior.

Similar to what we observed in female canaries, there may also be a differential role for AR and ER activation during song development in naturally-raised male canaries. Although juvenile males express high levels of both receptors in HVC, AR-expression persists throughout the breeding season, while ER-expression is significantly down-regulated (Gahr and GarciaSegura, 1996; Gahr and Metzdorf, 1997). Thus in both male and female canaries, AR and ER signaling pathways are both necessary during song ontogeny, but once vocal skills have been acquired, AR pathways appear to play the more dominant role in the maintenance and reacquisition of song performance.

Extensive evidence exists for sex hormones' influence on both brain plasticity, as well as language development, cognition, learning, and memory (Anthoni et al., 2012; Bailey et al., 2017; Frick et al., 2015; Friederici et al., 2008; Hahn et al., 2016; Hamson et al., 2016; Hawley et al., 2013; Leonard and Winsauer, 2011; Postma et al., 2000; Schaadt et al., 2015; Vahaba and Remage-Healey, 2018). Nonetheless, there are still gaps in our understanding of the complex interplay between sex hormones, brain, and behavior. Closing these knowledge gaps might help explain the contradictory results obtained in the use of sex hormones for the treatment of cognitive declines and psychiatric disorders (Beer et al., 2006; Cherrier et al., 2007; Elias and Kumar, 2007; Resnick et al., 2017; Wolf et al., 2000). Our findings provide a further piece of this incomplete puzzle. Understanding the hormone pathways and gene cascades involved in the formation, maintenance, and re-acquisition of vocal motor skills in our female canary model system has the potential to both further our knowledge on motor learning and motor skill savings, as well as to inspire better treatments for disorders affecting learning and memory. 


\section{Materials and Methods}

\section{Subjects}

For this study, one-year old female domesticated canaries (Serinus canaria) were taken from the breeding colony of the Max Planck Institute for Ornithology in Seewiesen, Germany. Experimental procedures were conducted according to the guidelines of the Federation of European Animal Science Associations (FELASA) and approved by the council for animal experimentation of the Danish ministry of environment and food.

\section{Hormone treatment}

In the DHT control group ( $\mathrm{DHT}_{1}+$ ), birds were subcutaneously implanted with $8 \mathrm{~mm}$ silastic tubes (Dow Corning, Midland, MI; ID: $1.47 \mathrm{~mm}$ ) filled with $5 \alpha$-dihydrotestosterone (DHT). After 2 months of DHT implantation, birds were either sacrificed in order to collect brains for Golgi-Cox processing $(n=5)$, or DHT implants were removed for subsequent singing ability confirmation, by subcutaneous implantation with $8 \mathrm{~mm}$ silastic tubes filled with testosterone $(n=5)$. In the DHT re-treatment group $\left(\mathrm{DHT}_{2}+, \mathrm{n}=6\right)$, birds were subcutaneously implanted with $8 \mathrm{~mm}$ silastic tubes filled with testosterone, which were removed after consolidation of song, approximately 6 months later. After 2.5 months in which birds did not produce song, a second $8 \mathrm{~mm}$ silastic tube containing DHT was implanted, and birds were sacrificed 2 months later.

\section{Hormone analysis}

Throughout the experiments, blood samples were collected from the birds' right wing veins using heparinized hematocrit capillaries (Brand, Wertheim, Germany). Directly after blood collection, samples were centrifuged at 3000 RPM for $10 \mathrm{~min}$ to separate cells from plasma,

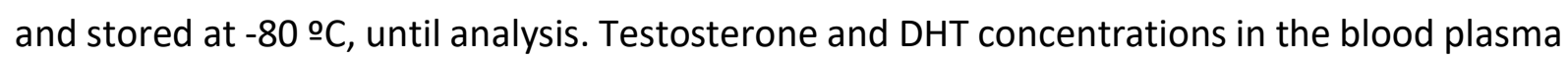
were determined by radioimmunoassay (RIA) after extraction and partial purification on diatomaceous earth (glycol) columns, following the procedures described in (Goymann et al., 2001; Goymann et al., 2006). Plasma levels of both testosterone and DHT during the different hormone treatments are shown in Table 1. 
Table 1: Plasma levels of testosterone (T) and $5 \alpha$-dihydrotestosterone (DHT) during different hormone treatments.

\begin{tabular}{|l|c|l|c|l|}
\hline Treatment & T levels (pg/ml) $^{\text {Significance }}{ }^{1}$ & DHT levels (pg/ml) $^{\text {Significance }^{1}}$ \\
\hline control & $116 \pm 32$ & & $36 \pm 5$ & \\
\hline $\mathrm{DHT}_{1}+$ & $99 \pm 12$ & NS & $2296 \pm 200$ & $\mathrm{P}<0.05$ \\
\hline $\mathrm{DHT}_{2}+$ & $108 \pm 18$ & NS & $4638 \pm 1052$ & $\mathrm{P}<0.001$ \\
\hline
\end{tabular}

${ }^{1}$ P-values of comparisons between different hormone treatments against control values ANOVA with Dunett's correction for multiple comparisons against 1 control).

\section{Song recordings and analysis}

Birds were kept in sound attenuating chambers and the vocal activity of each bird was recorded using Sound Analysis Pro 2.0 (SAP, Tchernichovski et al., 2004). Vocalizations were segmented into individual syllables with the fully automated Feature Batch module in SAP by applying an amplitude threshold to the sound wave. To filter out non-song vocalizations as much as possible, syllables were only included when produced within a song bout of at least $750 \mathrm{~ms}$. A song bout was defined as a sequence of sounds traversing the amplitude threshold with an interval of no more than $100 \mathrm{~ms}$. For each syllable, frequency modulation (FM), duration (d), inter-syllable interval (i), and syllable rate (SR) were calculated and stored in MySQL 5.1 tables (Oracle, Redwood Shores, CA; http://www.mysql.com). The syllable rate was defined for each syllable as: $\operatorname{SR}_{a}=\left(d_{a}+i_{a}\right)^{-1}$, where $d_{a}$ is the duration of syllable $a$, and $i_{a}$ is the interval between the end of syllable a and the beginning of the consecutive syllable within the same song bout, irrespective of syllable type.

To investigate the dynamic change of song features over the course of the experiment, daily histograms were obtained by rounding individual SR or FM values to the nearest integer, and plotting the number of times those integers occurred each day. Developmental correlation plots for both SR and FM were produced by calculating the Pearson product-moment correlation coefficient (CC) between the average daily histogram of 1 week at the time of song stabilization and all other recorded days. A non-linear exponential curve (1) was fitted through the $\mathrm{CC}$ values and song parameters were considered stable as soon as the daily increase in similarity dropped below $0.001 \mathrm{CC} /$ day.

$$
F(x)=a+\frac{b}{1+\left(\frac{c-x}{d}\right)}
$$




\section{Spine and dendrite quantification}

Brains were collected immediately after birds were sacrificed and processed for Golgi-Cox staining using the FD Rapid Golgi Stain kit (FD NeuroTechnologies, Columbia, MD) as previously described in Vellema et al. (2019), in order to produce Golgi-stained brain sections for spine quantifications. For each bird, z-stacks of nucleus HVC were obtained from three brain sections with a Nikon Eclipse Ti microscope (Nikon, Tokyo, Japan), equipped with a 60x oil immersion lens (CFI Plan Apo VC 60x Oil). The outline of each HVC section was delineated in ImageJ (http://rsb.info.nih.gov/ij/), and $100 \mu \mathrm{m}^{2}$ non-overlapping regions of interests (ROIs) were randomly placed within the boundaries of HVC prior to the quantifications. Quantifications were carried out as previously described in Vellema et al. (2019). All quantifications were conducted by an experimenter that was blind to the experimental condition of the animals.

\section{Statistical analysis}

To determine differences in hormone levels, data from all experiments were pooled and plasma values during the different hormone treatments were compared using a one-way ANOVA with Dunett's correction for multiple comparisons against one control value (untreated birds). The average daily syllable production was compared using a Friedman test, followed by a Wilcoxon signed-rank test to compare time points.

Song pattern similarities during the $1^{\text {st }}$ and $2^{\text {nd }}$ hormone treatments were established by calculating Pearson's CC between the 7-day average of the SR or FM patterns from stabilized song during the $1^{\text {st }}$ treatment with the 7 -day pattern average from stabilized song during the $2^{\text {nd }}$ treatment, constituting the within-individual CC. Between-individual CCs were determined by cross-correlating the 7-day pattern average during the $1^{\text {st }}$ hormone treatment of each bird with the 7-day pattern average during the $2^{\text {nd }}$ hormone treatment of each of the other birds. Differences between within-individual CCs and between-individual CCs were compared using paired-samples t-tests.

All statistical tests were two-tailed, and considered significant if the coincidence interval of $95 \%$ was exceeded. Measurement values in the text are given as means \pm SEM, unless stated otherwise. 


\section{Acknowledgements}

The authors would like to thank Ingrid Schwabl, Monika Trappschuh and Wolfgang Goymann for performing and analyzing the hormone radioimmunoassays. This work was supported by the European Union's Horizon 2020 (H2020) Marie Skłodowska-Curie grant nr. 701660 to MV, and the Max-Planck-Gesellschaft (MPG) to MR and MG. 


\section{References}

Anthoni H, Sucheston LE, Lewis BA, Tapia-Páez I, Fan X, Zucchelli M, Taipale M, Stein CM, Hokkanen M-E, Castrén E, Pennington BF, Smith SD, Olson RK, Tomblin JB, Schulte-Körne G, Nöthen M, Schumacher J, Müller-Myhsok B, Hoffmann P, Gilger JW, Hynd GW, NopolaHemmi J, Leppanen PHT, Lyytinen H, Schoumans J, Nordenskjöld M, Spencer J, Stanic D, Boon WC, Simpson E, Mäkelä S, Gustafsson J-Å, Peyrard-Janvid M, lyengar S, Kere J. 2012. The Aromatase Gene CYP19A1: Several Genetic and Functional Lines of Evidence Supporting a Role in Reading, Speech and Language. Behav Genet 42:509-527. doi:10.1007/s10519-012-9532-3

Bailey DJ, Makeyeva Y V., Paitel ER, Pedersen AL, Hon AT, Gunderson JA, Saldanha CJ. 2017. Hippocampal Aromatization Modulates Spatial Memory and Characteristics of the Synaptic Membrane in the Male Zebra Finch. Endocrinology 158:852-859. doi:10.1210/en.2016-1692

Balthazart, J., Boseret, G., Konkle, A., Hurley, L., and Ball, G. (2008). Doublecortin as a marker of adult neuroplasticity in the canary song control nucleus HVC. Eur. J. Neurosci. 27, 801817.

Beer TM, Bland LB, Bussiere JR, Neiss MB, Wersinger EM, Garzotto M, Ryan CW, Janowsky JS. 2006. Testosterone Loss and Estradiol Administration Modify Memory in Men. J Urol 175:130-135. doi:10.1016/S0022-5347(05)00049-2

Blair Simpson H, Vicario DS. 1990. Brain pathways for learned and unlearned vocalizations differ in zebra finches. J Neurosci 10:1541-1556. doi:10.1523/jneurosci.10-0501541.1990

Bolhuis, J. J., Okanoya, K., and Scharff, C. (2010). Twitter evolution: converging mechanisms in birdsong and human speech. Nat. Rev. Neurosci. 11, 747-759. doi:10.1038/nrn2931.

Brenowitz EA, Lent K. 2002. Act locally and think globally: Intracerebral testosterone implants induce seasonal-like growth of adult avian song control circuits. Proc Natl Acad Sci U SA 99:12421-12426. doi:10.1073/pnas.192308799

Brenowitz EA, Lent K. 2001. Afferent input is necessary for seasonal growth and maintenance of adult avian song control circuits. J Neurosci 21:2320-2329. doi:10.1523/jneurosci.21- 
07-02320.2001

Brzozowski AM, Pike ACW, Dauter Z, Hubbard RE, Bonn T, Engström O, Öhman L, Greene GL, Gustafsson J-Å, Carlquist M. 1997. Molecular basis of agonism and antagonism in the oestrogen receptor. Nature 389:753-758. doi:10.1038/39645

Carson-Jurica MA, Schrader WT, O’Malley BW. 1990. Steroid Receptor Family: Structure and Functions. Endocr Rev 11:201-220. doi:10.1210/edrv-11-2-201

Chen, Z., Ye, R., and Goldman, S. a. (2013). Testosterone modulation of angiogenesis and neurogenesis in the adult songbird brain. Neuroscience 239, 139-148. doi:10.1016/j.neuroscience.2012.12.043.

Cherrier MM, Matsumoto AM, Amory JK, Johnson M, Craft S, Peskind ER, Raskind MA. 2007. Characterization of verbal and spatial memory changes from moderate to supraphysiological increases in serum testosterone in healthy older men. Psychoneuroendocrinology 32:72-79. doi:10.1016/j.psyneuen.2006.10.008

Devoogd T, Nottebohm F. 1981. Gonadal hormones induce dendritic growth in the adult avian brain. Science (80- ) 214:202-204. doi:10.1126/science.7280692

Diotel, N., Charlier, T. D., Lefebvre d'Hellencourt, C., Couret, D., Trudeau, V. L., Nicolau, J. C., et al. (2018). Steroid Transport, Local Synthesis and Signaling within the Brain : Roles in Neurogenesis, Neuroprotection, and Sexual Behaviors. Front. Neurosci. 12, 84. doi:10.3389/fnins.2018.00084.

Dittrich F, Ramenda C, Grillitsch D, Frankl-Vilches C, Ko MC, Hertel M, Goymann W, ter Maat A, Gahr M. 2014. Regulatory mechanisms of testosterone-stimulated song in the sensorimotor nucleus HVC of female songbirds. BMC Neurosci 15:1-16. doi:10.1186/s12868-014-0128-0

Doupe AJ, Solis MM, Kimpo R, Boettiger CA. 2004. Cellular, circuit, and synaptic mechanisms in song learning. Ann N Y Acad Sci 1016:495-523. doi:10.1196/annals.1298.035

Elias A, Kumar A. 2007. Testosterone for schizophrenia. Cochrane Database Syst Rev. doi:10.1002/14651858.CD006197.pub2

Frankl-Vilches C, Kuhl H, Werber M, Klages S, Kerick M, Bakker A, de Oliveira EHC, Reusch C, Capuano F, Vowinckel J, Leitner S, Ralser M, Timmermann B, Gahr M. 2015. Using the 
canary genome to decipher the evolution of hormone-sensitive gene regulation in seasonal singing birds. Genome Biol 16:1-25. doi:10.1186/s13059-014-0578-9

Frick KM. 2015. Molecular mechanisms underlying the memory-enhancing effects of estradiol. Horm Behav 74:4-18. doi:10.1016/j.yhbeh.2015.05.001

Frick KM, Kim J, Tuscher JJ, Fortress AM. 2015. Sex steroid hormones matter for learning and memory: estrogenic regulation of hippocampal function in male and female rodents. Learn Mem 22:472-493. doi:10.1101/Im.037267.114

Friederici AD, Pannekamp A, Partsch C-J, Ulmen U, Oehler K, Schmutzler R, Hesse V. 2008. Sex hormone testosterone affects language organization in the infant brain. Neuroreport 19:283-286. doi:10.1097/WNR.0b013e3282f5105a

Fusani L, Metzdorf R, Hutchison JB, Gahr M. 2003. Aromatase inhibition affects testosteroneinduced masculinization of song and the neural song system in female canaries. $J$ Neurobiol 54:370-379. doi:10.1002/neu.10141

Gahr M. 1990a. Localization of androgen receptors and estrogen receptors in the same cells of the songbird brain. Proc Natl Acad Sci $U$ S A 87:9445-9448. doi:10.1073/pnas.87.23.9445

Gahr M. 1990b. Delineation of a brain nucleus: Comparisons of cytochemical, hodological, and cytoarchitectural views of the song control nucleus HVC of the adult canary. J Comp Neurol 294:30-36. doi:10.1002/cne.902940104

Gahr, M. (2004). Hormone-dependent neural plasticity in the juvenile and adult song system: What makes a successful male? Ann. N. Y. Acad. Sci. 1016, 684-703. doi:10.1196/annals.1298.025.

Gahr M, Flügge G, Güttinger H-R. 1987. Immunocytochemical localization of estrogen-binding neurons in the songbird brain. Brain Res 402:173-177. doi:10.1016/00068993(87)91063-8

Gahr M, Garcia-Segura LM. 1996. Testosterone-dependent increase of gap-junctions in HVC neurons of adult female canaries. Brain Res 712:69-73. doi:10.1016/00068993(95)01448-9

Gahr M, Metzdorf R. 1997. Distribution and Dynamics in the Expression of Androgen and 
Estrogen Receptors in Vocal Control Systems of Songbirds. Brain Res Bull 44:509-517. doi:10.1016/S0361-9230(97)00233-5

Galea, L. A. M., Uban, K. A., Epp, J. R., Brummelte, S., Barha, C. K., Wilson, W. L., et al. (2008). Endocrine regulation of cognition and neuroplasticity: Our pursuit to unveil the complex interaction between hormones, the brain, and behaviour. Can. J. Exp. Psychol. 62, 24760. doi:10.1037/a0014501.

Goymann W, East ML, Hofer H. 2001. Androgens and the role of female "hyperaggressiveness" in spotted hyenas (Crocuta crocuta). Hormones and behavior 39(1):83-92.

Goymann W, Geue D, Schwabl I, Flinks H, SchmidI D, Schwabl H, Gwinner E. 2006. Testosterone and corticosterone during the breeding cycle of equatorial and European stonechats (Saxicola torquata axillaris and S. t. rubicola). Hormones and behavior 50(5):779-785.

Hahn A, Kranz GS, Sladky R, Kaufmann U, Ganger S, Hummer A, Seiger R, Spies M, Vanicek T, Winkler D, Kasper S, Windischberger C, Swaab DF, Lanzenberger R. 2016. Testosterone affects language areas of the adult human brain. Hum Brain Mapp 37:1738-1748. doi:10.1002/hbm.23133

Hamson DK, Roes MM, Galea LAM. 2016. Sex Hormones and Cognition: Neuroendocrine Influences on Memory and LearningComprehensive Physiology. Hoboken, NJ, USA: John Wiley \& Sons, Inc. pp. 1295-1337. doi:10.1002/cphy.c150031

Hawley WR, Grissom EM, Martin RC, Halmos MB, Bart CLS, Dohanich GP. 2013. Testosterone modulates spatial recognition memory in male rats. Horm Behav 63:559-565. doi:10.1016/j.yhbeh.2013.02.007

Kafitz, K. W., Güttinger, H. R., and Müller, C. M. (1999). Seasonal changes in astrocytes parallel neuronal plasticity in the song control area HVc of the canary. Glia $27,88-100$.

Kirn, J., O'Loughlin, B., Kasparian, S., and Nottebohm, F. (1994). Cell death and neuronal recruitment in the high vocal center of adult male canaries are temporally related to changes in song. Proc. Natl. Acad. Sci. U. S. A. 91, 7844-7848.

Kornfeld J, Benezra SE, Narayanan RT, Svara F, Egger R, Oberlaender M, Denk W, Long MA. 2017. EM connectomics reveals axonal target variation in a sequence-generating network. Elife 6:1-20. doi:10.7554/eLife.24364 
Leonard ST, Winsauer PJ. 2011. The effects of gonadal hormones on learning and memory in male mammals: A review. Curr Zool 57:543-558. doi:10.1093/czoolo/57.4.543

Luine V, Serrano P, Frankfurt M. 2018. Rapid effects on memory consolidation and spine morphology by estradiol in female and male rodents. Horm Behav 104:111-118. doi:10.1016/j.yhbeh.2018.04.007

Nottebohm, F. (1981). A brain for all seasons: cyclical anatomical changes in song control nuclei of the canary brain. Science 214, 1368-1370. doi:10.1126/science.7313697.

Nottebohm, F., Nottebohm, M. E., Crane, L. A., and Wingfield, J. C. (1987). Seasonal changes in gonadal hormone levels of adult male canaries and their relation to song. Behav Neural Biol 47, 197-211.

Nottebohm F, Stokes TM, Leonard CM. 1976. Central control of song in the canary, Serinus canarius. J Comp Neurol 165:457-486. doi:10.1002/cne.901650405

Postma A, Meyer G, Tuiten A, van Honk J, Kessels RP., Thijssen J. 2000. Effects of testosterone administration on selective aspects of object-location memory in healthy young women. Psychoneuroendocrinology 25:563-575. doi:10.1016/S0306-4530(00)00010-X

Resnick SM, Matsumoto AM, Stephens-Shields AJ, Ellenberg SS, Gill TM, Shumaker SA, Pleasants DD, Barrett-Connor E, Bhasin S, Cauley JA, Cella D, Crandall JP, Cunningham GR, Ensrud KE, Farrar JT, Lewis CE, Molitch ME, Pahor M, Swerdloff RS, Cifelli D, Anton S, Basaria S, Diem SJ, Wang C, Hou X, Snyder PJ. 2017. Testosterone Treatment and Cognitive Function in Older Men With Low Testosterone and Age-Associated Memory Impairment. JAMA 317:717. doi:10.1001/jama.2016.21044

Sartor JJ, Balthazart J, Ball GF. 2005. Coordinated and dissociated effects of testosterone on singing behavior and song control nuclei in canaries (Serinus canaria). Horm Behav 47:467-476. doi:10.1016/j.yhbeh.2004.12.004

Schaadt G, Hesse V, Friederici AD. 2015. Sex hormones in early infancy seem to predict aspects of later language development. Brain Lang 141:70-76. doi:10.1016/j.bandl.2014.11.015

Smith, G. T., Brenowitz, E. a, Beecher, M. D., and Wingfield, J. C. (1997). Seasonal changes in testosterone, neural attributes of song control nuclei, and song structure in wild songbirds. J. Neurosci. 17, 6001-6010. 
Srivastava DP. 2012. Two-Step Wiring Plasticity - A mechanism for estrogen-induced rewiring of cortical circuits. J Steroid Biochem Mol Biol 131:17-23. doi:10.1016/j.jsbmb.2012.01.006

Tramontin, a. D., and Brenowitz, E. a. (2000). Seasonal plasticity in the adult brain. Trends Neurosci. 23, 251-258. doi:10.1016/S0166-2236(00)01558-7.

Tchernichovski, O., Lints, T., Deregnaucourt, S., and Mitra, P. P. (2004). Analysis of the entire song development: Methods and Rationale. Ann NY Acad Sci 1016, 348-363.

Thompson, C., and Brenowitz, E. (2005). Seasonal change in neuron size and spacing but not neuronal recruitment in a basal ganglia nucleus in the avian song control system. J. Comp. Neurol. 481, 276-283.

Vahaba DM, Remage-Healey L. 2018. Neuroestrogens rapidly shape auditory circuits to support communication learning and perception: Evidence from songbirds. Horm Behav 104:77-87. doi:10.1016/j.yhbeh.2018.03.007

Vellema, M., Hertel, M., Urbanus, S., Van der Linden, A., and Gahr, M. (2014). Evaluating the predictive value of doublecortin as a marker for adult neurogenesis in canaries (Serinus canaria). J. Comp. Neurol. 522, 1299-1315.

Vellema M, Rocha MD, Bascones S, Zsebők S, Dreier J, Leitner S, Van Der Linden A, Brewer J, Gahr M. 2019. Accelerated redevelopment of vocal skills is preceded by lasting reorganization of the song motor circuitry. Elife 8:1-26. doi:10.7554/eLife.43194

Voigt, C., and Leitner, S. (2008). Seasonality in song behaviour revisited: seasonal and annual variants and invariants in the song of the domesticated canary (Serinus canaria). Horm. Behav. 54, 373-378.

Wolf OT, Preut R, Hellhammer DH, Kudielka BM, Schürmeyer TH, Kirschbaum C. 2000. Testosterone and cognition in elderly men: a single testosterone injection blocks the practice effect in verbal fluency, but has no effect on spatial or verbal memory. Biol Psychiatry 47:650-654. doi:10.1016/S0006-3223(99)00145-6 